\title{
Foreseeability and causation in clinical negligence cases
}

\author{
Chris Morris, ${ }^{1}$ Tania Francis ${ }^{1}$ and Gautam Chawla*1
}

\section{Key points}

Suggests foreseeability will not be a difficult hurdle for a claimant to surmount in most cases, save for

in 'information' cases where it is the nature of the

information provided which is important.
Discusses why the 'but for' test remains the touchstone of causation in clinical negligence cases.
Highlights notable and important exceptions to the 'but for' principle which have been developed by the courts in recent years, much to a claimant's advantage.

\begin{abstract}
This article summarises the law on foreseeability and causation in clinical negligence cases. It focuses on what a claimant needs to prove and the development of the law in these areas.
\end{abstract}

\section{Introduction}

This is the second in a two-part series of articles dealing with the elements which must be proved to establish liability in a clinical negligence claim. The first article dealt with the first two elements, namely that a successful claimant needs to establish that a duty was owed by the healthcare practitioner to treat her with reasonable care/skill and that the duty was breached due to some substandard care. However, that is only the beginning of the story in these cases. It is also incumbent upon the claimant who has established the first two elements of her claim to also demonstrate that the breach caused some injury or damage, and that the particular injury or damage suffered was foreseeable.

Causation is far more important in medical cases than, for example, road traffic actions, because it is often common ground that the claimant had some illness before the negligence, whereas road users do not. The court always has to identify the natural history of the claimant's disease, absent the negligence, in clinical negligence cases in order to determine what difference the defendant's acts/omissions have made to the ultimate outcome.

'Hempsons, London, UK

${ }^{*}$ Correspondence to: Gautam Chawla

Email: g.chawla@hempsons.co.uk

Accepted 27 March 2019

DOI:10.1038/s41415-019-0414-4

\section{Foreseeability}

Foreseeability falls to be determined before the issue of causation is addressed. A claimant will only recover damages in circumstances where she can show that the damage is a reasonably foreseeable consequence of the practitioner's breach of duty. In most cases, this is not the basis of the defence; it is easy to see how injury is a foreseeable outcome of negligent clinical treatment. Indeed, in most clinical negligence cases the question as to whether the claimant's injury/outcome was foreseeable is wholly uncontentious.

However, there are circumstances where the claimant will fall at this hurdle, including cases where the healthcare practitioner is providing information as opposed to advice or treatment. The classic hypothetical example cited in the leading case of South Australia Asset Management Corp v York Montague Ltd is that of a doctor who negligently informs a mountaineer that he is fit to embark on a climb notwithstanding his suspect knee. ${ }^{1}$ The doctor will not be held liable for any injury the mountaineer suffers which is a foreseeable risk of mountaineering but has nothing to do with the state of his knee; for example, in an injury caused by an avalanche. While it could be argued that the mountaineer would not have embarked on the climb but for the negligent information provided by the doctor, and so would not have been on the mountain during the avalanche, in legal terms there is an insufficient causal connection between the injury and the negligent information for the mountaineer to succeed in any claim against the doctor.

The recent case of Khan v MNX followed this approach. ${ }^{2}$ It was held that a doctor, who had negligently failed to determine that a woman was a carrier for haemophilia, was not liable for all of the losses incurred by the woman in raising a child to whom she had later given birth and who suffered from both haemophilia and autism. The scope of the doctor's duty had only been to investigate the risk of haemophilia and, therefore, the doctor was not liable for a type of loss which did not fall within that scope; that is, the losses arising from the autism were irrecoverable but losses arising from the haemophilia were.

However, it is important to understand the distinction between information and advice cases. In the case of the hypothetical mountaineer, the doctor was being asked for information in respect of only one of the considerations that might influence the mountaineer's decision and which might affect his safety on the expedition (the condition of his knee). In a clinical context, such 'information' cases involve the healthcare professional providing information which the patient will weigh in the balance along with other considerations (in the mountaineer's case the avalanche risk, for example) when deciding on the course of action. This is different from 'advice' or 'consent' cases, in which the healthcare professional is advising the patient to take a particular course of action. 


\section{Causation}

Causation is often a difficult issue, not least because the law has evolved in this area from the simple 'but for' principle to notable, and not altogether coherent, exceptions.

\section{'But for'}

The basic tenet of causation is that the claimant must prove, on the balance of probabilities (that is, a likelihood of $51 \%$ or more), that any breach of duty has caused a foreseeable injury. At first blush, this appears to be a simple, comprehensible and logical test.

Take, for example, a hypothetical case involving a mandibular osteotomy to correct malocclusion, which results in a 'bad split', a postoperative infection and a very poor outcome for the patient. Let us assume that the patient has been properly consented for the procedure, including for the risk of infection. Independent expert evidence is adduced which concludes that the operative technique was deficient, hence the bad split, but that the split itself did not lead to any increased risk of postoperative infection and that, on the balance of probabilities, the infection would have occurred in any event. The patient will recover damages for the bad split and its consequences but not in respect of the infection and its after effects.

However, if the same patient can establish that she was not properly consented for that procedure and that but for the failure in the consenting process she would not have had the operation at all, she will recover in respect of both the bad split and the infection. Thus, it is easy to see why consent arguments are increasingly being run in clinical cases, particularly in light of the decision in Montgomery (as discussed in the previous article), which is of great assistance to potential claimants. ${ }^{3}$ However, even in consent cases, as a general rule, the claimant still needs to establish that she would have declined the procedure or made a different decision when faced with the information she should have been provided with. The case of A v East Kent, ${ }^{4}$ which followed hot on the heels of Montgomery is a prime example of this. The judge found that there was no need to warn of entirely theoretical risks in a case involving a child born with a chromosomal disorder and he went on to find that even if such risks had been discussed with the mother, she would have continued with the pregnancy and declined a termination in any event; the case failed.

\section{Limitations of the 'but for' test}

The 'but for' test has caused some difficulty in many cases and is increasingly being viewed as too blunt a tool with which to determine causation in clinical cases. It is for that reason that the courts have developed exceptions to the basic rule.

An oft quoted case is that of Gregg v Scott, which involved a negligent delay in diagnosing cancer. ${ }^{5}$ The evidence was that, on the balance of probabilities, even with a timely diagnosis the patient would not have survived as his prospects of survival were assessed at $42 \%$ (that is, less than $51 \%$ chance of survival). The complicating factor in this case was that the evidence also showed that, as a consequence of the delayed diagnosis, the patient's prospects of survival had reduced from $42 \%$ to approximately $25 \%$. Nonetheless, the court took an uncompromising view as to the strict application of the 'but for' test in clinical cases and found that the patient could not recover damages for his of loss of a chance of improved survival prospects because his prospects had never been more than $50 \%$.

\section{Exceptions to the basic rule}

The case of Bailey $v$ Ministry of Defence changed the issue of causation significantly, much to a claimant's advantage. ${ }^{6}$ The case involved postoperative vomiting, aspiration of the vomit, cardiac arrest and hypoxic brain injury. It was found that there had been a negligent failure to adequately resuscitate the claimant postoperatively. The evidence was that the aspiration had two causes: firstly, weakness caused by the consequences of the procedure which would have been present in any event absent any negligence; secondly, weakness caused by the negligent failure to adequately resuscitate her postoperatively. The court found that the claimant's weakness had resulted from both non-negligent and negligent causes, as described above. However, the court was not able to determine which of these causes was the dominant cause and, instead, found that each contributed materially to the overall weakness. On that basis, causation was established. It was held that in cases where medical science cannot establish whether 'but for' an act of negligence the injury would have been avoided but where science can establish that the contribution of the negligent cause to the injury was material, that is, more than negligible, the 'but for' test is modified and the claimant will succeed.

In the case of Chester $v$ Afshar, ${ }^{7}$ which many feel was wrongly decided, the court allowed the claimant to succeed where one would have thought she would have failed on the usual 'but for' principles. The defendant neurosurgeon had failed to warn the claimant of a $1-2 \%$ risk of paralysis arising from planned spinal surgery. That risk eventuated and the claimant brought a claim on the basis that she had not been adequately consented. There was no criticism of the procedure itself and it was accepted that the complication was one which was well recognised and which could occur non-negligently. It was also accepted that the risk of that complication arising would have been constant whoever had carried out the surgery and whenever the procedure had been performed. Moreover, the claimant was unable to say that, had she been warned of the risks, she would have never have submitted to the procedure. The best she could do was to say that she would not have had the operation at that particular time, but might simply have deferred it to seek a second opinion. It was accepted that the claim was bound to fail if the ordinary principles of causation (the 'but for' test) were applied because she would have had the surgery even if she had been properly warned. However, the court sought to recognise the loss of personal autonomy which the claimant had suffered as a result of being inadequately consented and permitted her to succeed in what was described as a 'modest departure' from the traditional principles of causation. There has been much criticism of the decision in Chester but it has not yet been overturned. However, it is clear that it will only apply in cases of negligent failure to warn patients about the risks of treatment, and not to other causation arguments.

\section{Conclusion}

While foreseeability is usually a straight forward issue, the law on causation is ever evolving and exceptions to the basic 'but for' principle have only made it easier for claimants to succeed. However, causation remains an essential and significant hurdle for any claimant to surmount.

\section{References}

1. South Australia Asset Management Corp v York Montague Ltd. 1996. UKHL 10.

2. Khan v MNX. 2018. EWCA Civ 2609.

3. Montgomery v Lanarkshire Health Board. 2015. UKSC 11.

4. A v East Kent Hospitals University NHS Foundation Trust 2015. EWHC 1038 (QB)

5. Gregg v Scott. 2005. UKHL 2.

6. Bailey $\vee$ The Ministry of Defence $\&$ Anor. 2008. EWCA Civ 883.

7. Chester v Afshar. 2004. UKHL 41 